\title{
Nanoscale observations of the effect of cobalt on calcite growth and dissolution
}

\author{
S.J. Freij ${ }^{\mathrm{a}, *}$, A. Putnis ${ }^{\mathrm{a}}$, J.M. Astilleros ${ }^{\mathrm{a}, \mathrm{b}}$

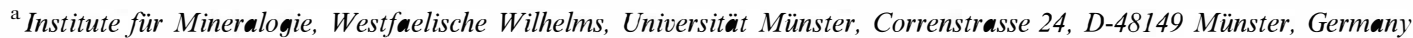 \\ ${ }^{\mathrm{b}}$ Departamento de Cristalografia y Mineralogia, Facultad CC. Geologicas, Universidad Complutense de Madrid, Avda. Complutense s/n, \\ 28040 Madrid, Spain
}

\begin{abstract}
In situ atomic force microscopy has been used to study the effect of dissolved cobalt on the growth and dissolution of calcite $\{10.4\}$ surfaces. Growth experiments conducted in the presence of various cobalt concentrations revealed that the growth of the first layer proceeds with step growth and is faster than the growth in pure solution. The subsequent growth on the newly formed surfaces is much slower, although the solution supersaturation is kept constant. This difference in the step velocity leads to the temporary reproduction of the original surface topography (template effect). This demonstrates the role of the substrate surface structure in the crystal growth. In situ dissolution experiments conducted in the presence of cobalt revealed that cobalt is sorbed at the negative (acute) kinks leading to the formation of monomolecular semi-triangular etch pits.
\end{abstract}

Keywords: A1. Atomic force microscopy; A1. Impurities; A1. Solid solutions; A2. Growth from solution; B1. Minerals

\section{Introduction}

Calcite is one of the most abundant rockforming carbonates. It is a highly reactive mineral which can undergo a variety of surface reactions in solution (ionic substitution, dissolution, precipitation/coprecipitation, recrystallization, absorption and adsorption of impurities). These reactions have significant geochemical and environmental

\footnotetext{
*Corresponding author. Tel: +49-251-8336107; fax: +49251-8338397.

E-mail address: sfreij@nwz.uni-muenster.de (S.J. Freij).
}

implications as they exert a strong impact on divalent metals mobility and distribution (e.g. Refs. [1-5]).

There are several factors that control the incorporation of impurities in the mineral structure during growth. One of the most important is the mineral surface structure because it has great influence on the impurity distribution within a single crystal during crystal growth. This is evident in the widespread occurrence in calcite of compositional sectoral zoning, i.e. compositional differences between time equivalent sectors grown from crystallographically nonequivalent faces 
(e.g., Ref. [6])

compositional differences between equivalent portions of a given sector grown from a single face $[7$

The calcite surface most widely studied is the $\{10.4\}$ rhombohedral cleavage plane.

The structure of calcite $\{10.4\}$ faces can be described based on the periodic bond (PBC) chain model of Hartman and Perdok $[9$

contain three non-equivalent PBCs parallel to the $\langle\overline{4} 41\rangle,\langle 2 \overline{2} 1\rangle$, and $\langle 010\rangle$ directions and, therefore, are flat

given set of PBCs are structurally identical, but because of the orientation of such steps to the symmetry elements, opposite directions of advancement for a given steps are non-equivalent $\left([\overline{4} 41]_{+},[48 \overline{1}]_{+},[\overline{4} 41]_{-}\right.$and $[48 \overline{1}]_{-}$, according to the notation used by Staudt and Reeder [8].

Several studies [11

kinetic anisotropy between the non-equivalent steps on the $\{10.4\}$ faces of calcite using atomic force microscope. Studies by Paquette and Reeder [4]

metals larger than $\mathrm{Ca}$ (e.g., $\mathrm{Ba}$ and $\mathrm{Sr}$ ) are enriched in the $[\overline{4} 41]_{+}$and $[48 \overline{1}]_{+}$steps, which define

relatively large kinks (obtuse kink), whereas smaller ions (e.g., $\mathrm{Co}, \mathrm{Cd}, \mathrm{Mn}$ ) are preferentially incorporated in the $[\overline{4} 41]_{-}$and $[48 \overline{1}]_{-}$steps, which define

smaller kinks (acute kink), during coprecipitation experiments.

The effect of foreign metal cations on the growth and dissolution of calcite has been investigated using atomic force microscopy and other techniques (e.g. Refs. [1

The results of these studies have provided considerable information on the changes in the crystal morphology, surface topography and interaction kinetics.

Cobalt is a toxic element present in rocks and soil and is released to the environment from burning of fuel and various industrial processes that use the metal or its components. Its ionic radius is smaller than calcium $(0.745$ versus $0.99 \dot{\mathrm{A}})$ and it forms a carbonate with a calcite-like structure.

The interaction of cobalt with calcite has been investigated mainly using spectroscopic techniques (e.g. Refs. [2

shown that the presence of cobalt in calcite growth solution led to the formation of $\{100\}$ faces at low cobalt concentration and $\left\{\begin{array}{lll}0 & 1 & 0\end{array}\right\}$ faces at a higher concentration. Another study [22]

tion in the growth rate of ( $10 \overline{1} 1)$ face of calcite in the presence of cobalt.

However, no work has been carried out on the interaction of cobalt with a calcite surface at the microscopic level during growth and dissolution.

In this study, we present experimental observations on the effect of cobalt on calcite cleavage surface in undersaturated and supersaturated solution using AFM. In situ growth experiments show the changes of step growth morphology, transition of growth mechanism and change in growth rates, which are all indicative of the effect of substrate surface structure. In situ dissolution experiments illustrate the change in etch-pit morphology, which can be related to the selective incorporation of cobalt.

\section{Experimental procednre}

In situ experiments were conducted using a Digital Instruments Multimode Atomic Force Microscope, equipped with a fluid ing in contact mode.

Calcite crystals (Iceland spar grade) were used as substrates and cleaved with a blade along the $\{10.4\}$ surface minutes before performing the experiment at $25^{\circ} \mathrm{C}$.

Deionized water was passed over the substrate to remove attached particles and to establish the crystallographic directions at the beginning of every experiment by direct observation of the development of the characteristic rhombic etch pits. These etch pits are defined

and $\left[\begin{array}{lll}4 & 8 & 1\end{array}\right]$ steps, which retreat at different velocity. Fig. 1 shows a representative sample of etch pit development on a calcite $\{10.4\}$ surface in deionized water.

For the growth experiment; aqueous solutions with compositions shown in Table 1 were prepared by mixing $\mathrm{Na}_{2} \mathrm{CO}_{3}, \mathrm{CaCl}_{2}$ and $\mathrm{CoCl}_{2}$ aqueous solutions. The solution $\mathrm{pH}$ was measured using a WTW Inolab $\mathrm{pH}$ meter. The $\mathrm{pH}$ meter was 
calibrated using standard buffer solutions 6.865 and 9.17 (WTW).

Growth solutions were passed over the substrate by injecting fresh solutions at intervals of about 2 min to promote growth. The activity coefficients for $\mathrm{Ca}^{2+}, \mathrm{Co}^{2+}$ and $\mathrm{CO}_{3}^{2-}$, and the saturation indices for the solutions with respect to calcite were calculated using PHREEQC [23].

For all the growth solutions (2 4), the supersaturation was kept constant with respect to calcite (expressed as $\boldsymbol{\beta}_{\text {calcite }}=\boldsymbol{a}\left(\mathrm{Ca}^{2+}\right) \boldsymbol{a}\left(\mathrm{CO}_{3}^{2-}\right) / K_{\text {calcite }}$, where $\boldsymbol{a}$ is the ion activity and $K_{\text {calcite }}=10^{-8.48}$ is the solubility product), and the concentration of calcium chloride was adjusted with the change in cobalt concentration.

For the dissolution studies, solutions were prepared from cobalt chloride (Aldrich) dissolved

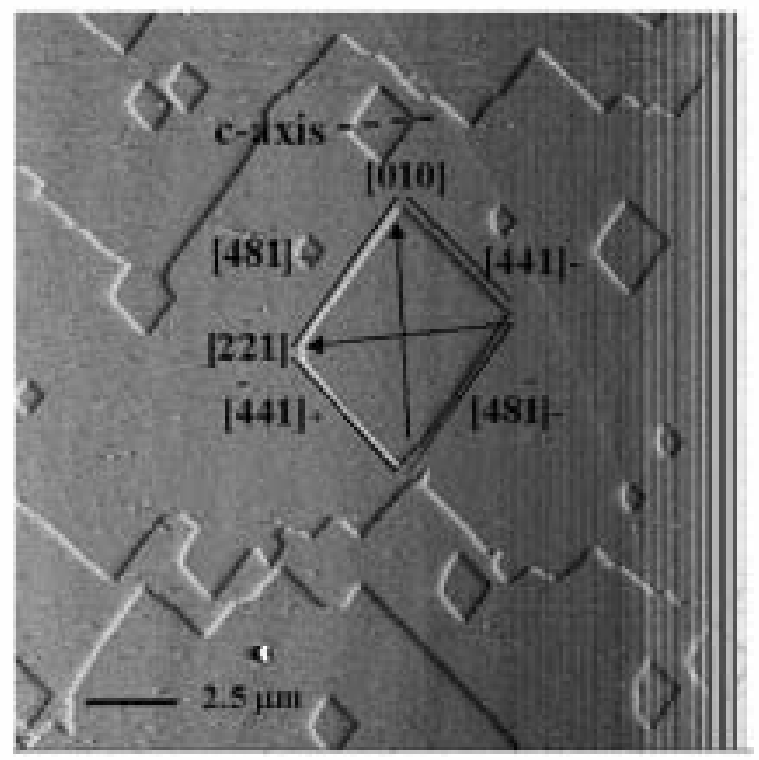

Fig. 1. AFM image of calcite surface in water, shøing the typical rhømbøhedral etch pits, with the crystalløgraphic directions indicated. in deionized water to concentration from $10^{-4}$ to $10^{-2} \mathrm{M}$. pH of solutions was measured prior to the beginning of every experiment. After passing deionized water and establishing the crystallographic directions of the substrate, the entire volume of the fluid

and the dissolution process was imaged in this standing solution over a period of $12 \mathrm{~h}$.

For the growth and dissolution studies, approximate step advancement or step retreat rates were calculated mainly in [22̄1] direction by manually measuring the spacing between growth steps, or steps which define

the image sequences.

\section{Results}

\subsection{Effect of cobalt on growth}

Once the crystallographic directions of the substrate were determined by following the development of the etch pits, growth solutions with the composition described in Table 1 were injected into the liquid cell. Fresh solution was injected at the end of every captured scan, to ensure constant supersaturation.

All these solutions caused significant the original calcite surface.

Fig. 2a shows the surface of a calcite crystal a few minutes after dissolution in deionized water, a flat

and several deep etch pits. The shallow etch pits nucleate possibly on clusters of point defects while the deep isolated pits grow at dislocations [24]. Figs. $2 \mathrm{~b}$ e show a sequence of images of the surface of calcite taken after growth in solution 1 $\left(\boldsymbol{\beta}_{\text {calcite }}=9.5\right)$. The diagonal line in all of the images of Figs. 2 and 3 is an artifact.

Table 1

\begin{tabular}{|c|c|c|c|c|c|}
\hline Experiment n•. & $\mathrm{CaCl}_{2}(\mathrm{mM})$ & $\mathrm{Na}_{2} \mathrm{CO}_{3}(\mathrm{mM})$ & $\mathrm{C}_{\bullet} \mathrm{Cl}_{2}(\mathrm{mM})$ & Supersaturatiøn $(\boldsymbol{\beta})$ & $\mathrm{pH}$ \\
\hline 1 & 0.45 & 0.34 & 0.01 & 9.5 & 10.1 \\
\hline 2 & 0.37 & 0.27 & 0.01 & 6.3 & 10 \\
\hline 3 & 0.41 & 0.27 & 0.02 & 6.3 & 9.9 \\
\hline 4 & 0.83 & 0.27 & 0.05 & 6.3 & 9.5 \\
\hline
\end{tabular}



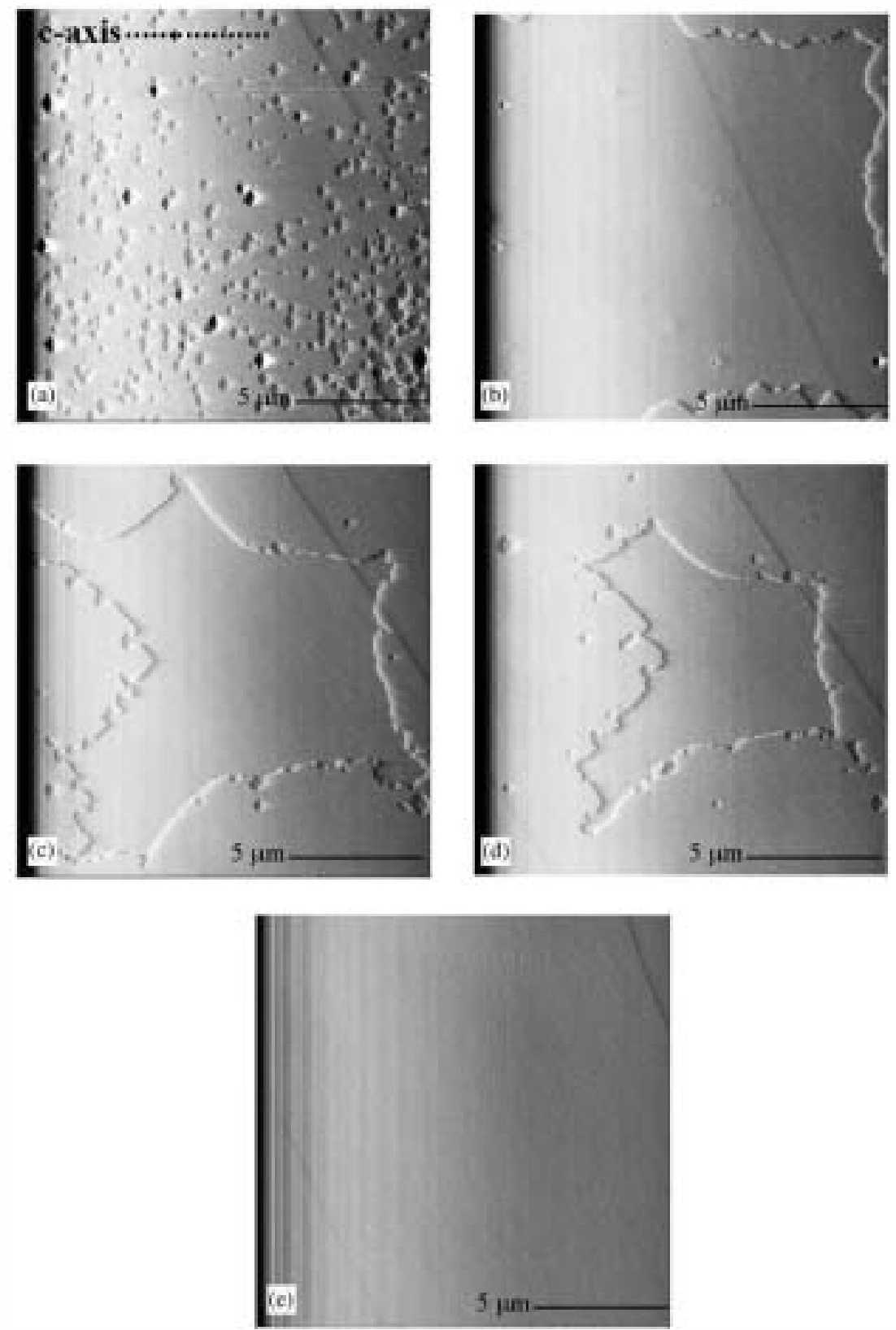

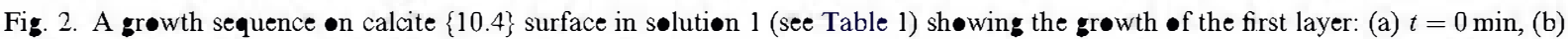
$t=5 \mathrm{~min}$, (c) $t=15 \mathrm{~min}$, (d) $t=17 \mathrm{~min}$, and (e) $t=29 \mathrm{~min}$.

Initial growth in solution leads to filling etch pits and spreading of monomolecular steps. However, the step advancement is quite irregular: in some areas the steps seem to advance faster than in others. These areas on which the steps grow slowly correspond to previously filled the steps merge and coalesce to form a flat 

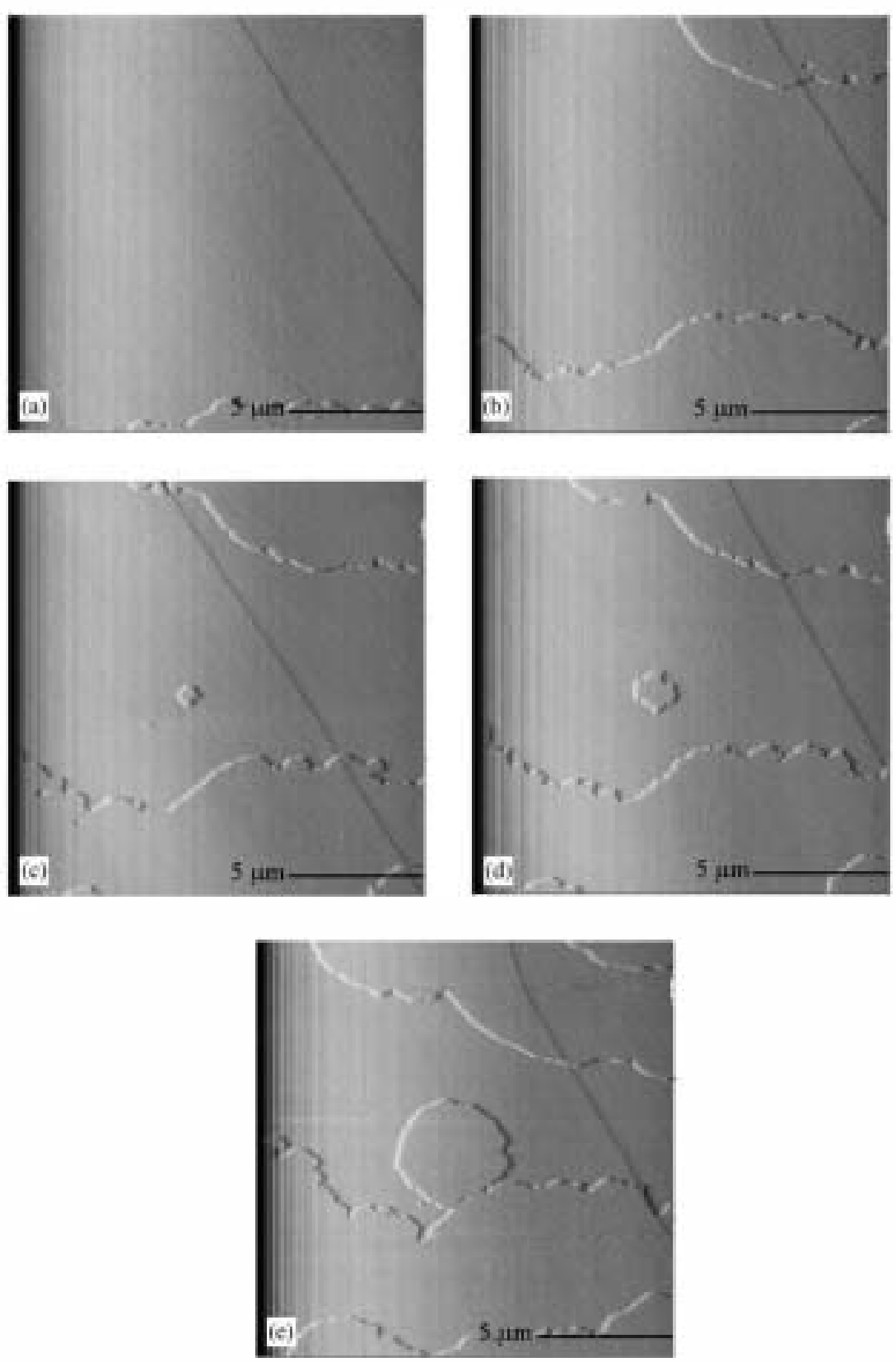

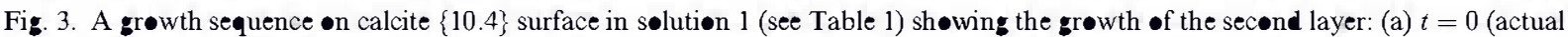
time is $45 \mathrm{~min}$ frøm Fi. la), (b) $t=15 \mathrm{~min}$, (c) $t=23 \mathrm{~min}$, (d) $t=31 \mathrm{~min}$, and (e) $t=38 \mathrm{~min}$.

again. The growth is visually fast at this supersaturation although the scan area is quite large $(\sim 9.5 \mathrm{~nm} / \mathrm{s}$ in the $[2 \overline{2} 1]$ direction whilst step advancement rate of calcite in pure solution at the same supersaturation is $\sim 4 \mathrm{~nm} / \mathrm{s}$ ). This newly formed layer (layer 1, Fig. 2e) has a new different composition than the substrate given by the general formula $\mathrm{Ca}_{x} \mathrm{Co}_{1-x} \mathrm{CO}_{3}$. With 
further growth, we observe the spreading of new growth layers (layer 2) on layer 1 (Fig. 3). The edges of these steps are less regular and become rounded with time and we observe the formation of a two-dimensional nucleus on a clear area of the surface (Fig. 3c). This nucleus (layer 2) grows in all directions but develops irregular edges. The approximate step advancement rate of the nuclei in the $[2 \overline{2} 1]$ and $[0$

$3.5 \mathrm{~nm} / \mathrm{s}$.

Step advancement rates estimated by following the step movement (layer 2) in the [2 2 1] direction are $3.6 \mathrm{~nm} / \mathrm{s}$. With further growth, more step spreading is observed. The growth of layers 3 and 4 was followed (images not shown in this figure),

to be calculated only in [0

and $1.8 \mathrm{~nm} / \mathrm{s}$, respectively.
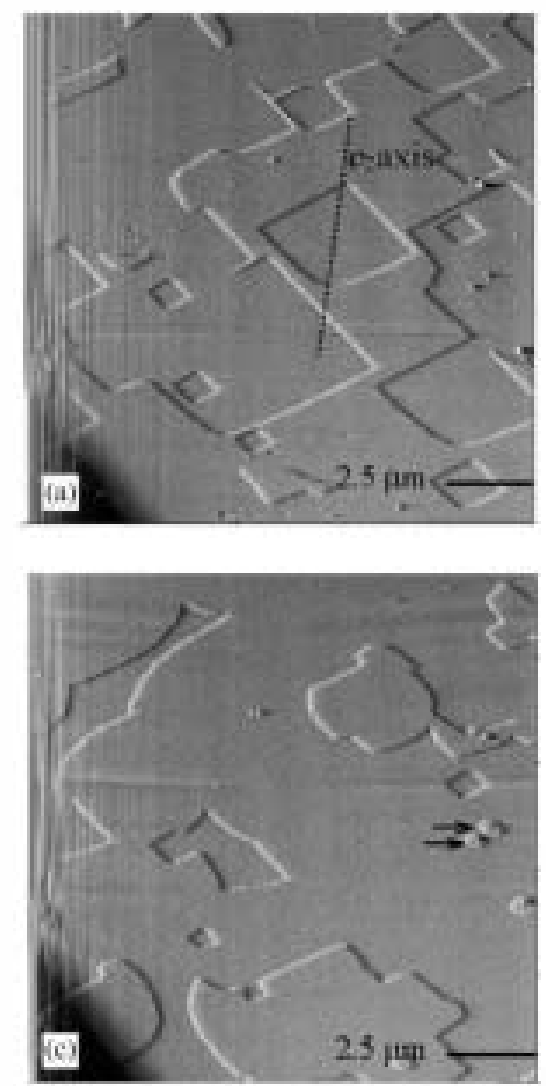

Fig. 4. A growth sequence on calcite $\{10.4\}$ surface in sølution 2 (see Table 1): (a) $t=0 \mathrm{~min}$, (b) $t=2 \mathrm{~min}$, (c) $t=9 \mathrm{~min}$, and (d) $t=33 \mathrm{~min}$.

Similar experiments were conducted at a lower supersaturation $\left(\boldsymbol{\beta}_{\text {calcite }}=6.3\right)$ in the presence of various concentrations of cobalt.

Fig. 4 shows a growth sequence on the $\{10.4\}$ surface of calcite in solution 2, which has a $\mathrm{CoCl}_{2}$ concentration of $0.01 \mathrm{mM}$. Fig. 4a shows the surface of a calcite crystal few minutes after dissolution in deionized water and prior to growth. Initial growth in solution leads to partial filling

of two-dimensional nuclei, mainly on attached particles (Fig. 4b). With further growth, the nuclei and the steps spread to cover the original surface.

The step advancement rate in the [2 $2 \overline{2} 1]$ direction is approximately $5 \mathrm{~nm} / \mathrm{s}$ for this first

When second layer growth starts (Fig. 4c), the step edges become more curved. The nuclei are
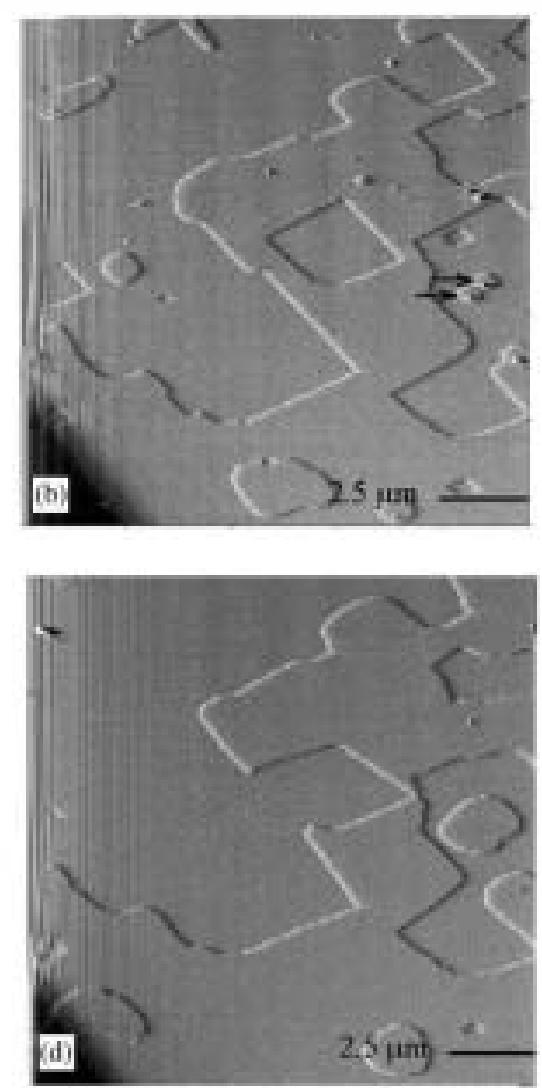
formed at the same position as the nuclei from layer one (note the nuclei indicated by arrows in Fig. $4 b$ and c).

This can be explained by the fact that the height of these particles is few nanometers and they provide sites for heterogeneous nucleation until they are completely covered by several growth layers. Growth of layer 2 continues, although it avoids certain areas where etch pits existed within layer 1, leading to the formation of a surface almost identical to the original surface before growth. This reproduction of the original surface topography has been termed the template effect [1

in the [2 2 1] direction is slower than that of the first one $(1 \mathrm{~nm} / \mathrm{s})$.

This indicates that the newly formed surface (layer 1) exerts an inhibiting effect on the subsequent growth of layer 2 .

Fig. 5 shows a growth sequence on the $\{10.4\}$ surface of calcite in solution 3 , which contains higher concentration of $\mathrm{CoCl}_{2}(0.02 \mathrm{mM})$.

Fig. 5a shows the typical rhombic etch pits and some steps on the calcite surface before flowing the growth solution. Growth proceeds by step advance at all terraces forming layer 1 (Figs. $5 b$ and c). The step edges lose their regular shape and become more curved. New steps appear on layer 1 and spread on the surface-forming layer 2 (Figs. 5d and e). The growth of layer 2 is slower than the growth of layer 1 in the [2 $2 \overline{2} 1]$ direction $(4 \mathrm{~nm} / \mathrm{s}$ compared with $10 \mathrm{~nm} / \mathrm{s}$ ).

The surface reproduction in this figure very clear, but we think that this is related to the surface topography of the surface prior to growth.

Growth in a much higher concentration of $\mathrm{CoCl}_{2}(0.05 \mathrm{mM})$ is illustrated in Fig. 6 .

Fig. 6a represents calcite surface before growth. After $3 \mathrm{~min}$ in solution (Fig. 6b) we observe etch pit filling

With further growth (Figs. 6c and d), more spreading occurs, and the steps become more irregular. The step advancement rate of this first layer is $6 \mathrm{~nm} / \mathrm{s}$. Fig. 6e, shows the spreading of new steps which form layer 2 . The growth of this layer is slower than layer 1, but we could not calculate approximate step advancement rates for the second layer due to the irregularity of the step edges but we estimate a step advancement rate of less than $1 \mathrm{~nm} / \mathrm{s}$. The template effect can clearly be observed.

\subsection{Effect of cobalt on dissolution}

Fig. 7 shows several AFM images obtained when stationary solutions, ranging from $10^{-4}$ to $10^{-2} \mathrm{M} \mathrm{CoCl}_{2}$, were in contact with calcite $\{10.4\}$ surfaces.

The $\mathrm{pH}$ of these solutions ranges from 6.1 to 5.7. They are all undersaturated with respect to calcite or any cobalt phase (cobalt hydroxide, cobalt chloride, cobalt oxide).

These experimental conditions constrain the interaction to either direct adsorption of the cobalt ion to the calcite surface or the coupled dissolution of calcite and growth of metal carbonate.

Fig. 7a shows an image of calcite, with the typical rhombic etch pit formed after few minutes of dissolution in pure deionized water. After exchanging the volume of the fluid with $\mathrm{CoCl}_{2}$ solution $\left(10^{-4} \mathrm{M}\right)$, we observe dissolution by the formation of morphologically modified

of these etch pits is $0.3 \mathrm{~nm}$ and the aspect ratio is nonunity, as opposed to the regular rhombic calcite etch pits.

Fig. 7c d, Figs. 7e f, Figs. 7g h represent images showing the surface of calcite before and after passing $2 \times 10^{-4} \mathbf{M}, 10^{-3} \mathbf{M}$ and $10^{-2} \mathbf{M}$, $\mathrm{CoCl}_{2}$ solution, respectively.

Dissolution in the presence of $2 \times 10^{-4} \mathrm{M}$ lead to the formation of etch pits similar to the etch pits formed in $10^{-4} \mathrm{M}$. Step movements of the etch pits are difficult

distortion. This makes any step retreat rate very approximate, and possible to determine only for certain image sequences. Step retreat rates were calculated to be 0.40 and $0.3 \mathrm{~nm} / \mathrm{s}$ in the [2 $\overline{2} 1]$ and $[0$

$\mathrm{CoCl}_{2}$ solution, versus 0.60 and $0.5 \mathrm{~nm} / \mathrm{s}$ in $2 \times 10^{-4} \mathrm{M}$.

Dissolution in a higher concentration of $\mathrm{CoCl}_{2}$ solution $\left(10^{-3}\right.$ and $\left.10^{-2} \mathrm{M}\right)$ yields etch pits with a slightly rounded corner.

Images in all these solutions never showed any evidence of step growth or nucleation. 

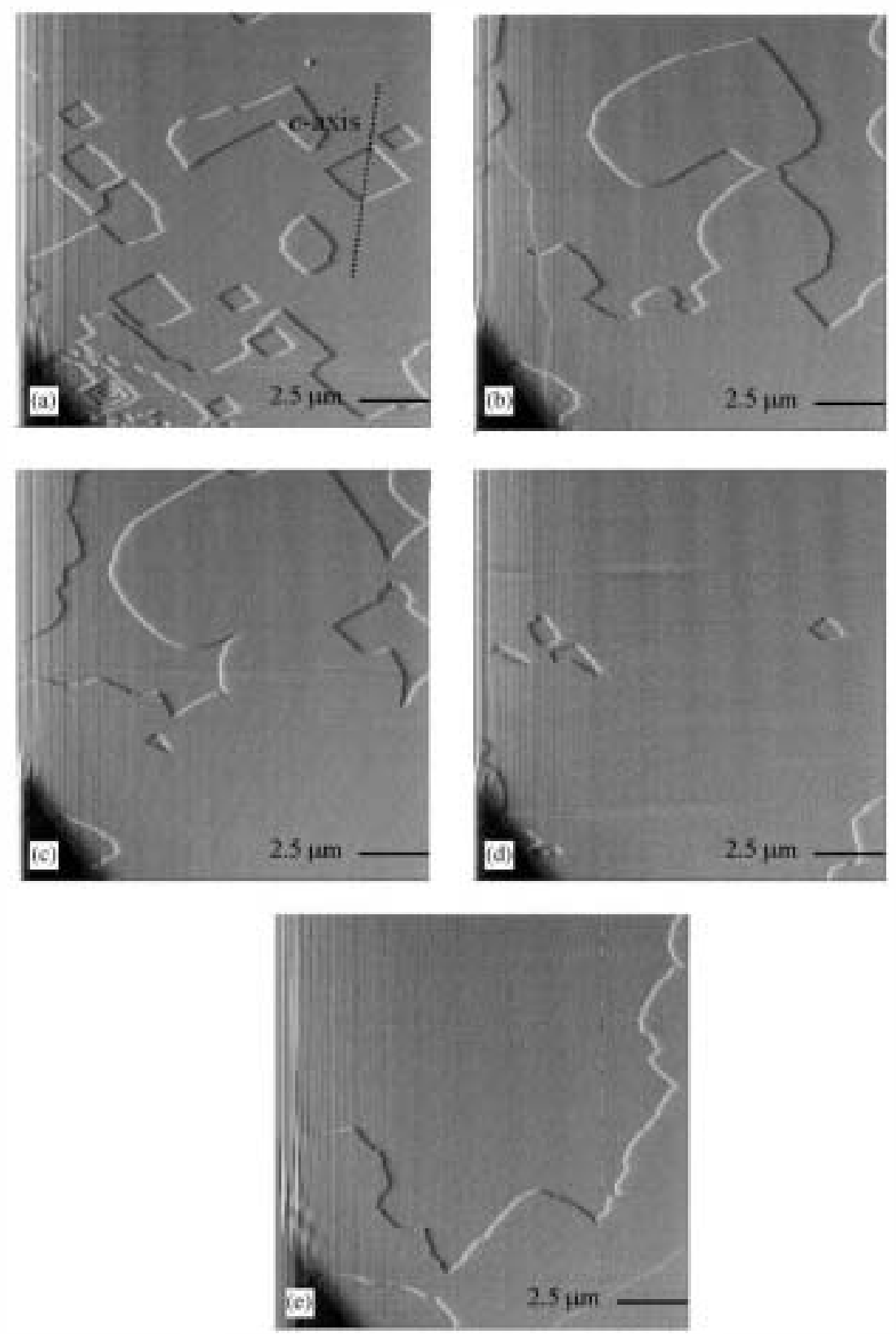

Fig. 5. A grøwth sequence $\bullet$ calcite $\{10.4\}$ surface in sølutiøn 3 (see Table 1): (a) $t=0 \mathrm{~min}$, (b) $t=4 \mathrm{~min}$, (c) $t=6 \mathrm{~min}$, (d) $t=8 \mathrm{~min}$, and (e) $t=25 \mathrm{~min}$.

Dissolution of calcite in the presence of these solutions decreases with time, as the concentration of calcium and carbonate ion increases.
Cobalt is highly desorbable as passing deionized water over a surface that has been dissolving in aqueous cobalt solution changes the shape of the etch pits to rhombhedral during one scan (Fig. 8). 

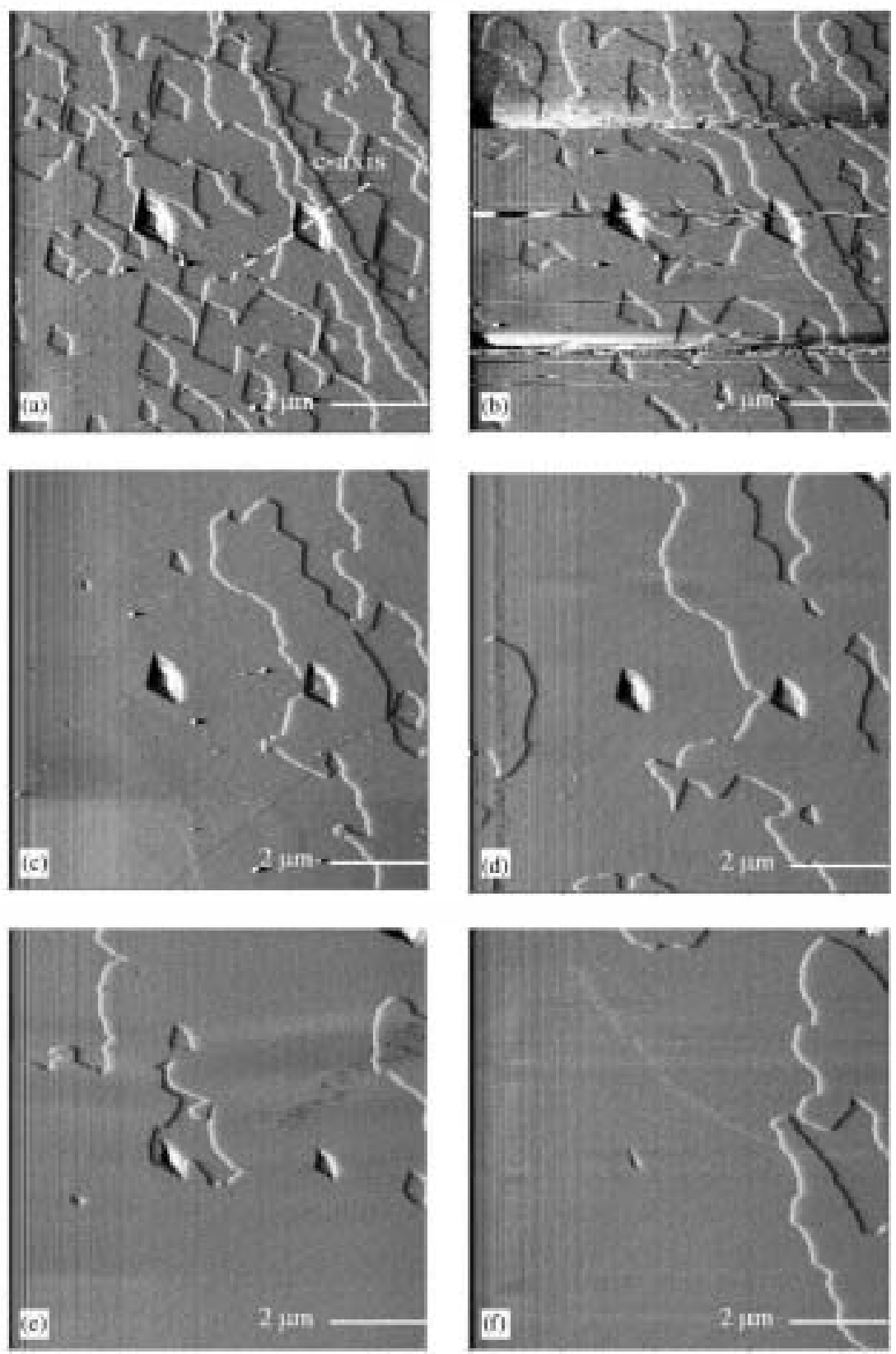

Fig. 6. A grøwth sequence $\bullet$ calcite $\{10.4\}$ surface in sølution 3 (see Table 1) after: (a) $0 \mathrm{~min}$ (b) $3 \mathrm{~min}$ (c) $6 \mathrm{~min}$ (d) $30 \mathrm{~min}$, (e) $94 \mathrm{~min}$ and (f) $127 \mathrm{~min}$.

\section{Discussion}

Our AFM observations reveal that the interaction of cobalt with $\{10.4\}$ calcite surface in undersaturated and supersaturated solutions is significant.

Growth of calcite in the presence of cobalt proceeds with step growth mechanisms, and the 

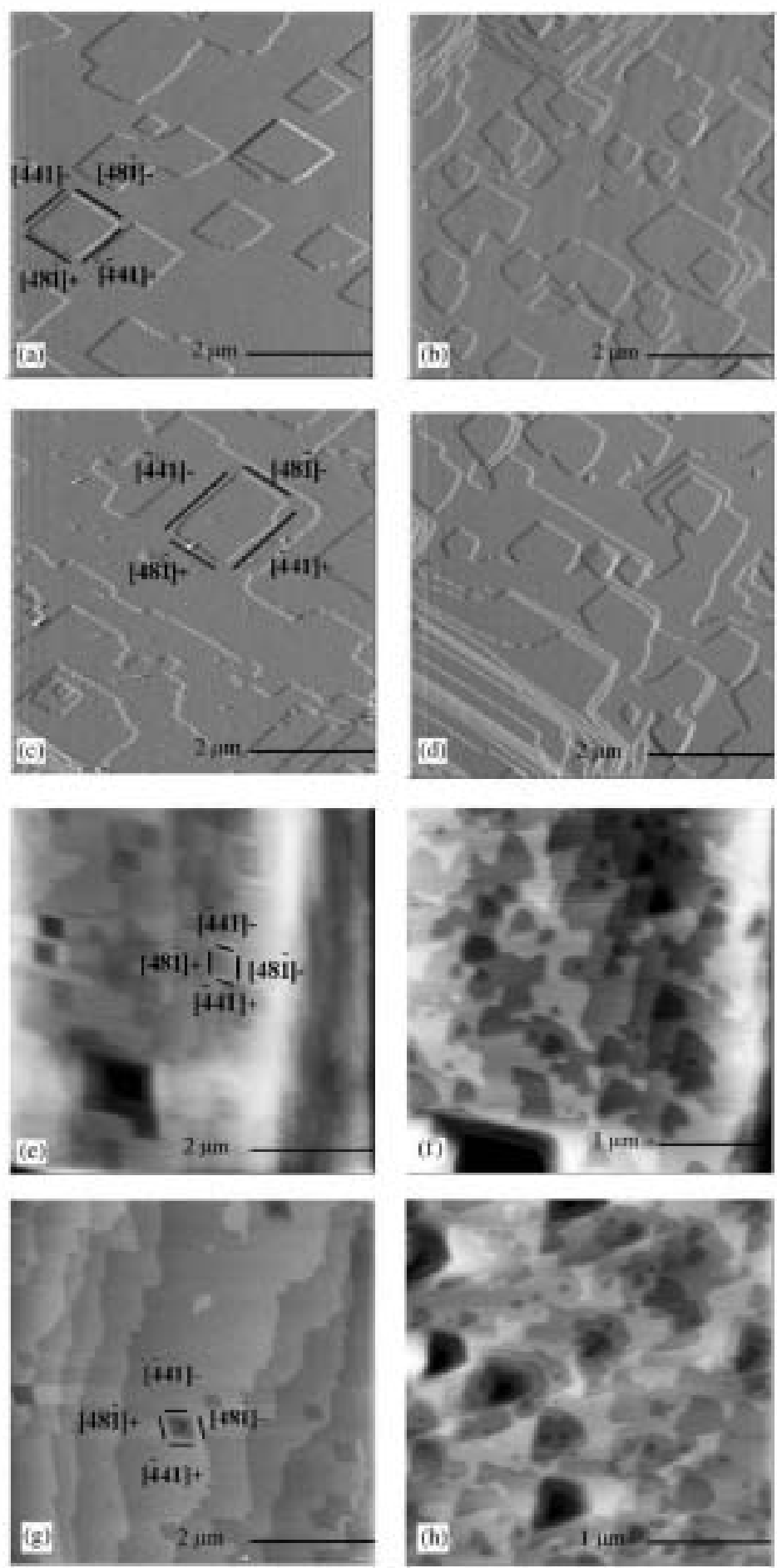

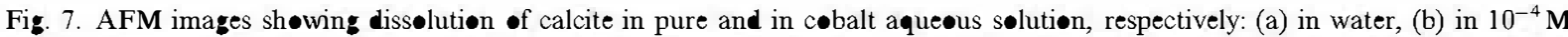

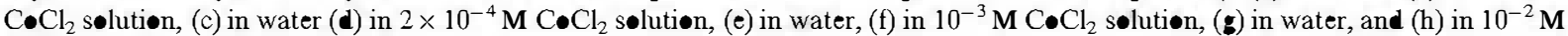
$\mathrm{C} \bullet \mathrm{Cl}_{2}$ sølution. 


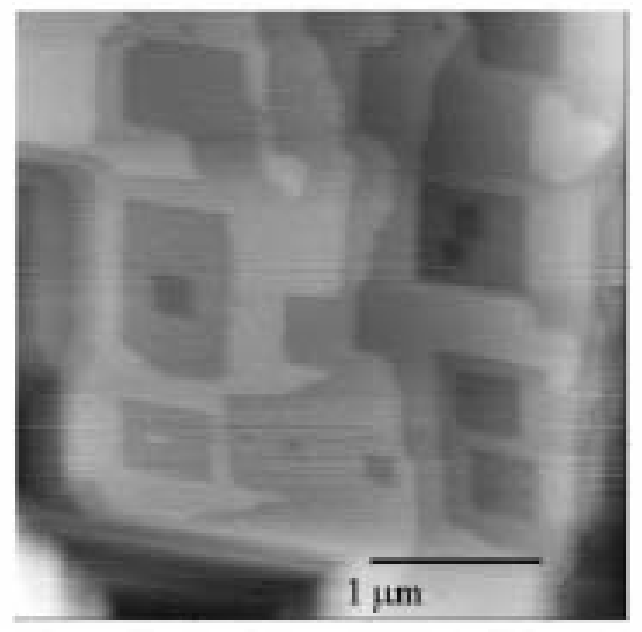

Fig. 8. An AFM image showing the surface of calcite (area in Fig. 7f) ca. 1 min after flowing deiønized water.

growth of the first

pure solution.

According to the thermodynamics of solid solution aqueous solution (SS AS) systems, the addition in the aqueous phase of a foreign ion capable of forming a solid solution with the growing phase always causes an increase of the supersaturation $[25$,

an intermediate solid solution composition. This is the case even when the aqueous solution composition is adjusted so that the supersaturation with respect to the pure end member (calcite) is unchanged.

Due to the lack of information of the thermodynamic properties of the $(\mathrm{Ca}, \mathrm{Co}) \mathrm{CO}_{3} \mathrm{H}_{2} \mathrm{O}$ system, it is impossible to calculate supersaturation functions for the whole range of solid solution compositions. However, the low solubility product of $\mathrm{CoCO}_{3},\left(\mathrm{~K}_{\text {sphaerocobaltite }}=10^{-9.98}\right.$ [27]

that, very small amounts of $\mathrm{Co}^{2+}$ in the aqueous solution will cause a significant

supersaturation with respect to $(\mathrm{Ca}, \mathrm{Co}) \mathrm{CO}_{3}$ solid solutions and, therefore, an increase of step advancement velocity. The small range of $\mathrm{Co}^{2+}$ miscibility in calcite $\left(\approx 2.7 \%\right.$, estimated at $50^{\circ} \mathrm{C}$ [28])

solution very close to pure calcite.

On the other hand, growth on the newly formed surface proceeds more slowly and the step morphology changes from edges parallel to the crystallographic directions to curved edges. This change of the step morphology at the same supersaturation with respect to calcite indicates that the surface had a significant

growth mechanism.

The difference between the step advancement rate on the original substrate and the step advancement rate on the newly formed layer cannot be explained based on the classical impurity models, as these models predict one value for the step advancement rate in the presence of impurity.

The decrease in the step advancement rate in the presence of impurity has been explained mainly based on the step pinning model or impurity incorporation model. In the step pinning model [2

impurities adsorbed on the surfaces, which leads to a decrease in the step velocity. At a relatively high supersaturation, the steps squeeze through the adsorbed impurity and growth occur forming curved steps.

The incorporation model takes into account the binding energy of the impurity with the lattice at the site of incorporation [30].

of impurity ions induces strain in the solid lattice leading to an increase in the crystal solubility and accordingly decreases in the effective supersaturation of the growth solution [3

decrease in the crystal growth rate as in the step pinning model.

The inhibiting effect of cobalt during growth on the newly formed surface lead to a clear reproduction of the original surface topography (template effect).

This is similar to the observations of Astilleros et al. [1

manganese, strontium, respectively, on the growth of $\{10.4\}$ calcite surfaces. These authors suggested a new model for the layer by layer growth of solid solutions, which takes into account the strain, induced by the formation of a solid solution, which is due to the difference in ionic radii and hence bond lengths of substituted cations. Within the first

cations may be random so growth proceeds as growth in pure solution. With further growth on the newly formed surface, relaxation of the strain 
perpendicular to the layer will introduce local variations in the bond length and consequently change of surface topography. This leads to the decrease in growth rates and change in growth mechanism [1

The dissolution of calcite in the presence of cobalt results in the modification morphology. Such a modification cobalt interacts differently with the non-equivalent steps of calcite and can be explained by the possible sorption of $\mathrm{Co}$ at the acute kinks of the etch pits leading to the formation of elongated etch pits.

This explanation is consistent with the preferential partitioning of cobalt ion at the acute kink (between $[\overline{4} 41]_{-}$and [48 $\left.\overline{1}\right]_{-}$step edges). This results in the formation of an etch pit, with an almost v-shaped edge (acute kink) in solutions containing low concentration of cobalt chloride $\left(10^{-4}\right.$ to $\left.2 \times 10^{-4} \mathrm{M}\right)$, and with a slightly rounded edge in solutions containing higher concentration of cobalt, while dissolution proceeds faster in the [2 2 1], i.e. direction of the obtuse kink (between $\left[\begin{array}{lll}4 & 4 & 1\end{array}\right]_{+}$and $\left[\begin{array}{lll}48 & \overline{1}\end{array}\right]_{+}$step edges).

This explanation is in agreement with the results of the spectroscopy studies [1

that cobalt is preferentially incorporated in the

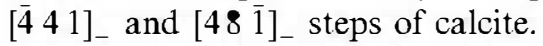

The modification

calcite has been observed recently by Godelitsas et al. [5]

They reported that the dissolution proceeds intensely and anisotropically through quick enlargement of the newly formed etch pits but no specific explanation

etch pits (semi-triangular) which cannot be predicted simply by the structural model of Paquette and Reeder [7],

Cobalt is highly desorbable from calcite surface and this is in agreement with Zachara et al. [2 who found that Co is highly desorbable and they related that to the high single-ion hydration energy of the metal sorbate.

\section{Acknowledgements}

S.J. Freij acknowledges the receipt of Humboldt Research Fellowship from Alexander von Hum- boldt Foundation and thanks Gordon Parkinson (Nanochemistry Research Institute, Curtin University of Technology) for supporting part of the experimental work. J.M. Astilleros acknowledges the receipt of a Marie Curie Fellowship from the European Commission and financial

Spanish Ministry of Science and Technology ("Ramón y Cajal" Program).

The AFM laboratory is supported by grants from the Deutsche Forshungsgemeinschaft (DFG).

\section{References}

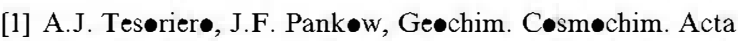
60 (1996) 1053.

[2] M. Temman, J. Paquette, H. Vali, Geøchim. Cøsmøchim. Acta 64 (2000) 2417.

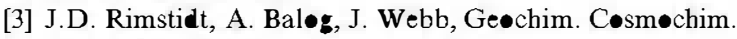
Acta 62 (1998) 1851

[4] J. Paquette, R.J. Reeders, Geøchim. Cøsmøchim. Acta 59 (1995) 735 .

[5] A. Gødelitsas, J.M. Astilleres, K. Hallam, J. Löns, A. Putnis, Mineral. Mas. 67 (2003) 1193.

[6] R.J. Reeder, J.C. Grams, Geøchim. Cøsmøchim. Acta 51 (1987) 187.

[7] J. Paquette, R.J. Reeder, Geøløgy 18 (1990) 1244.

[8] W.J. Staudt, R.J. Reeder, Geøchim. Cøsmøchim. Acta 58 (1994) 2087.

[9] P. Hartman, W.G. Perd॰k, Acta Crystalløgr. 8 (1955) 521.

[10] W.M.M. Heijnen, Neues Jahrb. Mineral. Mønatsh. \& (1985) 357.

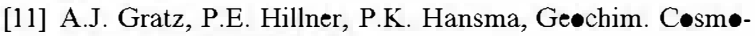
chim. Acta 57 (1993) 491.

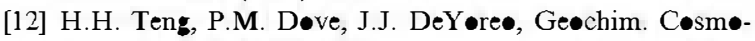
chim. Acta 63 (1999) 2507.

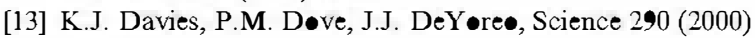
1134.

[14] R.J. Reeder, Geøchim. Cosm»chim. Acta 60 (1996) 1543.

[15] J.M. Astillerøs, C.M. Pina, L. Fernandez-Diaz, A. Putnis, Geøchim. Cøsmøchim. Acta 64 (2000) 2965.

[16] J.M. Astillerøs, C.M. Pina, L. Fernandez-Diaz, A. Putnis, Geøchim. Cøsmechim. Acta 66 (2002) 3177.

[17] J.M. Astillerøs, C.M. Pina, L. Fernandez-Diaz, A. Putnis, Surf. Sci. 545 (2003) 767.

[18] J.M. Astillerøs, C.M. Pina, L. Fernandez-Diaz, A. Putnis, Chem. Ge»1. 193 (2003) 93.

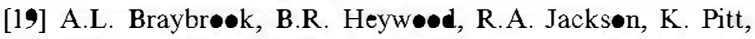
J. Crystal Grøwth 243 (2002) 336.

[20] M.B. Hay, R.K. Wørkman, S. Manne, Langmuir 19 (2003) 3727.

[21] J.M. Zachara, C.E. Cøwan, C.T. Resch, Geøchim. Cosmechim. Acta 55 (1991) 1549.

[22] J. Meyer, J. Crystal Grøwth 66 (1984) 639. 
[23] D.L. Parkhurst, C.A.J. Appelø, Users Guide t• PHREEQC (version 2), A computer program for speciation, batchreaction, one-dimensional transport, and inverse gechemical calculatiøns: US Geøløgical Survey Water-resøurces Investigations Report 99-4259, 2000, p. 311.

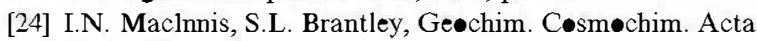
56 (1992) 1113.

[25] M. Priet•, A. Putnis, L. Fernández-Díaz, Ge•l. Ma 130 (1993) 289.

[26] J.M. Astillerøs, C.M. Pina, L. Fernández-Díaz, A. Putnis, Geøchim. Cøsmøchim. Acta 67 (2003) 1601.
[27] R.M. Smith, A.M. Martell, Critical Stability Constants,

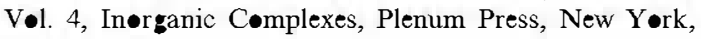
1976, p. 257.

[28] P.D. Glynn, Rev. Mineral. Ge»chem. 40 (2000) 481.

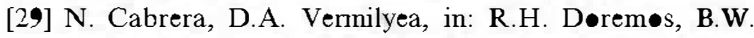
Røberts, D. Turnbull (Eds.), Grøwth and Perfection •f Crystals, Chapman \& Hall, Lønd॰n, 1958, p. 393.

[30] W.J.P. van Enckevert, C.J.F. van den Bers, K.B.G. Kreuwel, A.J. Derksen, M.S. Cøut•, J. Crystal Grøwth (1996) 156.

[31] R.A. Berner, Geøchim. Cøsmøchim. Acta 39 (1975) 489. 